\title{
Peran Promosi Melalui Iklan Katalog dalam Keputusan Pembelian Konsumen (Studi Kasus Pada Minimarket Indomaret di Kota Bengkalis)
}

\author{
Afis $^{1}$, Tri Handayani ${ }^{2}$ \\ 1,2 Jurusan Administrasi Niaga, Politeknik Negeri Bengkalis, Riau, Indonesia.
}

\begin{abstract}
Abstrak. Era digital ini begitu banyak strategi promosi online yang dapat dikembangkan oleh pelaku bisnis sehingga dirasakan promosi secara offline salab satunya dengan kalatog menjadi alternative kedua dalam bisnis. Penelitian ini bertujuan untuk. mengetahui pengaruh promosi melalui iklan katalog terbadap keputusan pembelian dengan studi kasus pada Minimarket Indomaret di Kota Bengkalis. Permasalahan dalam penelitian ini adalah bagaimana pengarub iklan katalog terhadap keputusan pembelian yang dilakukan oleh konsumen dan seberapa besar pengarubnya. Adapun subjek dalam penelitian ini adalab konsumen Minimarket Indomaret dengan mengambil informasi dari 100 responden dengan menggunakan instrument kuesioner yang bersumber dari pengembangan isntrumen penelitian. Teknik dalam pengumpulan sampel secara purposive sampling dan kemudian hasil informasi dianalisis dengan analisis korelasi dan regresi. Hasil penelitian menunjukkean bahwa terdapat korelasi dan pengaruh signifikan promosi dengan iklan katalog terhadap keputusan pembelian konsumen yaitu sebesar 42,1\%. Hal ini menunjukean strategi promosi segara katalog berdampak dalam tercapainya target konsumen bagi suatu bisnis.
\end{abstract}

Kata kunci: Strategi Promosi, Iklan Katalog, Keputusan Pembelian, Konsumen.

Abstract. In this digital era, there are so many online promotion strategies that can be developed by business people, so that offline promotion is felt, one of which is by using a log as the second alternative in business. This study aims to determine the effect of promotion through catalog advertising on purchasing decisions with a case study at the Indomaret Minimarket in Bengkalis City. The problem in this research is how the effect of catalog advertising on purchasing decisions made by consumers and how much influence it has. The subjects in this study were consumers of the Indomaret Minimarket by taking information from 100 respondents using a questionnaire instrument that was sourced from the development of research instruments. The technique of collecting samples was purposive sampling and then the results of the information were analyzed using correlation and regression analysis. The results showed that there was a significant correlation and effect of promotion with catalog advertising on consumer purchasing decisions, namely $42.1 \%$. This shows that the catalog promotion strategy has an impact in achieve target consumers for a business.

Keywords: Promotion Strategy, Catalog Advertising, Purchase Decision, Consumers. 


\section{Pendahuluan}

Persaingan bisnis yang begitu tinggi membuat perusahaan terus berlomba untuk mempertahankan dan memenangkan persaingan pasar serta memperluas eksistensinya. Pebisnis akan terus berusaha untuk meningkatkan kualitas dan kuantitas mereka demi untuk meraih dan merebut pasar dan eksistensi usaha.

Salah satu industri yang sangat berkembang saat ini yaitu industri ritel, yang semakin hari semakin kompetitif. Banyaknya industri ritel pada saat ini menyebabkan masyarakat lebih banyak memiliki alternatif untuk memenuhi kebutuhan mereka. Beberapa contoh perusahaan ritel adalah minimarket, supermarket, shopping center, mall dan department store. Banyaknya industri ritel membuat setiap perusahaan harus mempersiapkan strategi pemasaran khususnya strategi promosi agar siap menghadapi persaingan dapat memenangkan pasar, perkembangan usaha dan untuk mendapatkan profit semaksimal mungkin yang pada akhirnya perusahaan dapat mencapai tujuannya.

Begitu banyak strategi promosi usaha yang dapat diterapkan oleh pelaku bisnis pada era digital ini, banyak strategi promosi online yang dapat dikembangkan oleh pelaku bisnis sehingga dirasakan promosi secara offline salah satunya dengan kalatog menjadi alternatif kedua dalam bisnis.

Indomaret merupakan salah satu perusahaan retail menjadi alternatif bagi konsumen khususnya Kota Bengkalis dalam memenuhi kebutuhan yang masih menggunakan katalog sebagai salah satu alat promosi. Disamping menggunakan strategi pemasaran lain, baik itu dibidang product, price, dan place namun aspek promosi Indomaret masih memilih katalog sebagai strategi promosinya. Berdasarkan fenomena ini maka tertarik untuk meneliti lebih lanjut bagaimana pengaruh strategi promosi iklan melalui katalog terhadap keputusan pembelian konsumen dengan studi kasus pada masyarakat Bengkalis.

\section{Literature Review}

Beberapa penelitian yang menjadi rujukan dalam penelitian ini yaitu, penelitian yang dilakukan oleh Ng'etich dan Auka (2019) dengan judul Influence of Advertising On Consumer Purchase Decision Of Sport Betting: A Case Study Of Students In Nakuru Town. Dimana tujuan dari penelitian ini adalah untuk mengetahui pengaruh iklan terhadap keputusan pembelian konsumen taruhan olahraga di kalangan mahasiswa di kampus universitas di kota Nakuru. Sampel 367 siswa dipilih untuk menilai pengaruh berbagai elemen iklan terhadap keputusan pembelian konsumen. Studi ini mengungkapkan terdapat hubungan yang signifikan antara iklan dan keputusan pembelian konsumen dan dapat secara efektif digunakan oleh pemasar untuk mempengaruhi konsumen untuk membeli produk / layanan mereka.

Penelitian yang dilakukan oleh Sidabalok dan Andriyani (2020) dengan judul Pengaruh Iklan Katalog Terhadap Keputusan Pembelian, dimana penelitian ini termasuk penelitian kuantitatif yang bertujuan untuk mengetahui pengaruh katalog iklan menuju keputusan pembelian Indomaret di Sindangsari Tanjung Bintang. Penelitian ini menunjukkan bahwa iklan katalog berkontribusi signifikan sebesar 57,3\% dalam mempengaruhi keputusan pembelian.

Penelitian berikutnya yang dilakukan oleh Santosa dan Fatma (2019) yang meneliti tentang Pengaruh Iklan Terhadap Keputusan Pembelian Merchandise C-corner di PT. Kereta Commuter Indonesia Jakarta. Penelitian ini bertujuan untuk mengetahui pengaruh iklan terhadap keputusan pembelian pada barang dagangan c-corner. Hasil penelitian menggambarkan bahwa Iklan mempengaruhi segara signifikan terhadap keputusan pembelian.

Penelitian berikutnya yang dilakukan oleh Tumulo (2017) dengan judul Pengaruh Iklan dan Positioning Merek Terhadap Keputusan Pembelian Konsumen Minuman Coca Cola, dimana Penelitian ini bertujuan untuk mengetahui pengaruh iklan dan positioning merek terhadap keputusan pembelian konsumen minuman Coca Cola. Penelitian ini dilakukan pada Indomaret Jl. Williem Iskandar Medan, dengan jumlah sampel 73 orang dan dianalisis 
maka diperoleh analisis jalur pengaruh iklan dan positioning merek terhadap keputusan pembelian yaitu Iklan berpengaruh positif dan signifikan terhadap positioning merek sebesar 73,3\%. Iklan berpengaruh positif dan signifikan terhadap keputusan pembelian konsumen sebesar 70,2 $\%$.

Penelitian berikutnya yang dilakukan oleh Moloku, Tampi dan Walangitan (2019) dengan judul Pengaruh Iklan Terhadap Keputusan Pembelian Produk Smartphone Oppo Di IT Center Manado. Pendekatan penelitian ini adalah pendekatan kuantitatif. Variabel independen adalah iklan dan variabel dependen adalah keputusan pembelian. Total sampel responden adalah 100 orang. Hasil penelitian yang diperoleh adalah nilai koefisien antara iklan dan keputusan pembelian termasuk rendah 0,394. Pengaruh iklan terhadap keputusan pembelian sangat rendah yaitu 0,1555 dan hasil analisis regresi linier sederhana diperoleh koefisien regresi positif sehingga arah pengaruh variabel iklan terhadap variabel keputusan pembelian adalah positif.

\section{Promosi (promotion)}

Menurut Kotler \& Armstrong dalam Heryanto (2015) memberi pengertian bahwa promosi merupakan fungsi pemberitahuan, pembujukkan, dan pengimbasan keputusan konsumen. Tjiptono dalam Heryanto (2015) menyatakan bahwa pada hakekatnya promosi adalah bentuk komunikasi pemasaran. Yang dimaksud komunikasi pemasaran adalah aktivitas pemasaran yang berusaha menyebarkan informasi, mempengaruhi/membujuk, dan atau mengingatkan pasar sasaran atas perusahaan dan produknya agar bersedia menerima, membeli, dan loyal pada produk yang ditawarkan perusahaan yang bersangkutan.

Menurut Kotler dan Keller dalam Heryanto (2015) memberi pengertian bahwa bauran (Promotional Mix) pemasaran adalah perangkat alat pemasaran yang digunakan perusahaan untuk mengejar tujuan pemasarannya. Sementara itu, menurut Kotler dan Armstrong dalam Heryanto (2015) menyatakan bahwa pada dasarnya terdapat konsep alat pemasaran taktis dan terkendali yang dilaksanakan secara terpadu untuk mendapatkan respon dari para pelanggannya.

\section{Iklan}

Iklan secara komprehensif adalah semua bentuk aktivitas untuk menghadirkan dan mempromosikan ide, barang, atau jasa secara nompersonal yang dibayar oleh sponsor tertentu. (Durianto dalam Kuspriyono,2018). Iklan juga merupakan segala bentuk presentasi nonpribadi dan promosi gagasan barang atau jasa oleh sponsor tertentu yang harus dibayar. Iklan merupakan cara yang berbiaya efektif dalam menyampaikan pesan, untuk membangun persepsi merek atau untuk mendidik orang (Kotler dalam Kuspriyono 2018). Iklan dapat mempengaruhi dua parameter kepuasan konsumen. Pertama, iklan dapat membentuk perceived quality yang kemudian akan mempengaruhi penilaian terhadap kualitas secara keseluruhan, dan pengaruh iklan semakin besar bila konsumen tidak dapat mengevaluasi kualitas sesungguhnya. Kedua, iklan dapat mempengaruhi perceived best: keyakinan bahwa suatu produk adalah yang terbaik dikelasnya dipengaruhi oleh citra merek. Oleh karena itu banyak perusahaan menyediakan biaya iklan yang besar untuk memperkuat citra merek dan kesadaran merek pada benak konsumen dengan tujuan iklan dapat membantu perusahaan dalam meraih konsumen baru dan meningkatkan kualitas merek.

Menurut Kotler \& Keller dalam Santoso dan Fatma (2019) formula AIDA merupakan formula yang paling sering digunakan untuk membantu perancangan suatu iklan.

1. Attention

Menimbulkan perhatian pelanggan, berarti semua pesan harus dapat menimbulkan perhatian dalam bentuk informasi yang telah disampaikan lewat media. Perhatian itu bertujuan secara umum atau khusus kepada calon pembeli atau konsumen yang akan dijadikan target sasaran.

2. Interest

Ketertarikan atas pesan yang telah disampaikan lewat media yang digunakan akan menimbulkan perasaan ingin tahu, ingin mengamati dan ingin mendengar serta melihat lebih seksama. 


\section{Desire}

Pemikiran terjadi dari adanya keinginan yang berkaitan dengan motif motivasi konsumen dalam membeli suatu produk.

4. Action

Tindakan terjadi dengan adanya keinginan kuat konsumen sehingga terjadi pengambilan keputusan.

\section{Keputusan Pembelian}

Menurut Kotler dalam Moloku, Tampi dan Walagitan (2019), keputusan pembelian adalah suatu keputusan yang dilakukan oleh konsumen, baik konsumen individu maupun pembeli organisasi melalui proses mental yang hampir sama dalam memutuskan produk dan merek apa yang akan dibeli. Keputusan pembelian adalah seleksi terhadap dua pilihan alternatif konsumen pada pembelian (Schiffman dan Kanuk dalam Moloku, Tampi dan Walagitan 2019).

Proses pembelian yang spesifik terdiri dari urutan kejadian sebagai berikut: pengenalan masalah, pencarian informasi, evaluasi alternatif, keputusan pembelian, dan perilaku pasca pembelian (Kotler dalam Sidabalok dan Andriayani, 2020). Kelima tahap tersebut tidak selalu terjadi, khususnya dalam pembelian yang tidak memerlukan keterlibatan tinggi dalam pembelian. Para konsumen bisa melewati beberapa tahap dan urutannya tidak sesuai.

\section{Metodologi Penelitian}

Metode yang digunakan dalam penelitian ini adalah analisis data kuantitatif dimana objek penelitian ini adalah konsumen Minimarket Indomaret Kota Bengkalis. Data diperoleh dengan menyebarkan kuesioner kepada sampel yaitu sebanyak 100 responden, dimana teknik pengumpulan sampel digunakan yaitu purposive sampling, kemudian dilakukan analisis korelasi dan regresi untuk menguji hipotesis dalam penelitian ini.

$\mathrm{Ha}=$ Diduga iklan katalog berpengaruh positif dan signifikan terhadap keputusan pembelian

Ho = Diduga iklan katalog tidak berpengaruh positif dan signifikan terhadap keputusan pembelian
Dengan asumsi ( $\left.\mathrm{t}_{\text {hitung }}\right)$ :

Ha diterima jika, $t_{\text {hitung }} \geq t_{\text {tabel, }}$, atau Sig $<$ 0,05

Ho diterima jika, $t_{\text {hitung }} \leq t_{\text {tabel, atau }}$ Sig $>$ 0,05

Berdasarkan penjelasan di atas, maka dapat dipetakan suatu definisi operasional variable sebagai berikut:

Tabel 1. Definisi operasional varibel penelitian.

\begin{tabular}{|c|c|c|c|}
\hline No Definisi Konsep & Definisi Operasional & Indikator & $\begin{array}{c}\text { Skala } \\
\text { Penilaian }\end{array}$ \\
\hline 1. Penklanan(X) & $\begin{array}{l}\text { Iklan merupakan cara yang } \\
\text { betbiaya efektifdalam } \\
\text { menyampakkan pesan, untuk } \\
\text { membangum persepsi merek } \\
\text { atan untuk mendidik orang. }\end{array}$ & $\begin{array}{l}\text { d. Attention } \\
\text { b. Interest } \\
\text { c. Desire } \\
\text { d. Action }\end{array}$ & Likent (1.5) \\
\hline $\begin{array}{ll}\text { 2. } & \text { Kequutusan } \\
& \text { Pembelian(Y) }\end{array}$ & 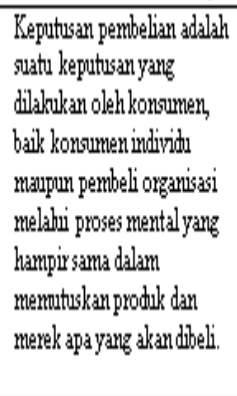 & $\begin{array}{l}\text { a. Pengenalan } \\
\text { kebutuhan } \\
\text { b. Pencanian } \\
\text { infomisi } \\
\text { c. Erabasi } \\
\text { altematif } \\
\text { d. Kepputsas } \\
\text { pembelian } \\
\text { e. Penlahupasca } \\
\text { pembelian. }\end{array}$ & $\operatorname{Liken}(1.5)$ \\
\hline
\end{tabular}

Sumber: Kotler dalam Kuspriyono (2018), Kotler \& Keller dalam Santoso dan Fatma (2019), Kotler dalam Moloku, Tampi dan Walagitan (2019), Kotler dalam Sidabalok dan Andriayani (2020).

\section{Hasil dan Pembahasan}

Adapun hasil analisis deskriptif mengenai variabel iklan katalog dapat dilihat pada Tabel 2 berikut ini:

Tabel 2. Rangkuman Deskriptif Variabel Iklan

\begin{tabular}{|c|c|c|c|c|c|c|c|c|c|c|}
\hline \multirow{2}{*}{\multicolumn{3}{|c|}{$\begin{array}{c}\text { Indikator } \\
\text { Iklan Katalog }\end{array}$}} & \multicolumn{5}{|c|}{ Distrihusi Frekuensi } & \multirow[t]{2}{*}{ Total } & \multirow[t]{2}{*}{ Mean } & \multirow[t]{2}{*}{ Ket. } \\
\hline & & & $\begin{array}{c}\text { SS } \\
5\end{array}$ & $\begin{array}{l}\mathrm{S} \\
4 \\
\end{array}$ & \multirow{2}{*}{$\begin{array}{c}\mathrm{RR} \\
\mathbf{3} \\
15\end{array}$} & \multirow{3}{*}{$\begin{array}{c}\text { TD } \\
\mathbf{2} \\
9\end{array}$} & \multirow{2}{*}{$\begin{array}{c}\text { STS } \\
1 \\
2\end{array}$} & & & \\
\hline Attention & 1 & & 34 & & & & & & & \\
\hline Areninon & 1 & Frek & 24 & & & & & 100 & 3,85 & Tinggi \\
\hline & & Skor & 120 & 200 & 45 & 18 & 2 & 385 & & \\
\hline Interest & 1 & Frek & 29 & 47 & 14 & 8 & 2 & 100 & 3,93 & Tinggi \\
\hline & & Skor & 145 & 188 & 42 & 16 & 2 & 393 & & \\
\hline Desire & 1 & Frek & 25 & 37 & 30 & 8 & - & 100 & 3,79 & Tinggi \\
\hline & & Skor & 125 & 148 & 90 & 16 & - & 379 & & \\
\hline & 2 & Frek & 27 & 37 & 26 & 10 & - & 100 & 3,81 & Tinggi \\
\hline & & Skor & 135 & 148 & 78 & 20 & - & 381 & & \\
\hline Action & 1 & Frek & 18 & 40 & 31 & 9 & 2 & 100 & 3,63 & Tinggi \\
\hline & & Skor & 90 & 160 & 93 & 18 & 2 & 363 & & \\
\hline Total & & Frek & 123 & 211 & 116 & 44 & 6 & 500 & 3,80 & Tinggi \\
\hline & & Skor & 615 & 844 & 348 & 88 & 6 & 1901 & & \\
\hline
\end{tabular}

Sumber: Data Olahan 2020

Dari Tabel tersebut dapat dijelaskan bahwa variabel yang paling mendominasi pernyataan iklan katalog dengan skor mean 3,93 adalah variabel interest dengan pernyataan iklan katalog indomaret membuat saya tertarik untuk melihat 
produk yang ditawarkan, pernyataan ini dapat diartikan bahwa iklan katalog di Minimarket Indomaret sangat berpengaruh besar dalam menimbulkan ketertarikan konsumen terhadap produk yang ditawarkan dikarenakan iklan tersebut mampu memberikan informasi mengenai produk yang diinginkan dan dibutuhkan oleh konsumen sehingga konsumen tertarik untuk melihat produk yang ditawarkan. Adapun hasil analisis deskriptif dari variabel keputusan pembelian dapat dilihat pada Tabel 3 berikut:

Table 3. Rangkuman Deskriptif Variabel keputusan Pembelian (Y)

\begin{tabular}{|c|c|c|c|c|c|c|c|c|c|c|}
\hline \multirow{2}{*}{\multicolumn{3}{|c|}{$\begin{array}{c}\text { Indikator } \\
\text { Keputusan Pembelian }\end{array}$}} & \multicolumn{5}{|c|}{ Distribusi Frekuensi } & \multirow[b]{2}{*}{ Total } & \multirow[b]{2}{*}{ Mean } & \multirow[b]{2}{*}{ Ket. } \\
\hline & & & SS & $S$ & $\mathrm{RR}$ & TD & STS & & & \\
\hline \multirow{4}{*}{$\begin{array}{l}\text { Pengenalan } \\
\text { kebutuhan }\end{array}$} & & Frek & 17 & 29 & 31 & 18 & 5 & 100 & \multirow[b]{2}{*}{3,30} & \multirow{4}{*}{ Sedang } \\
\hline & 1 & Skor & 85 & 116 & 93 & 36 & 5 & 330 & & \\
\hline & \multirow{2}{*}{2} & Frek & 18 & 28 & 27 & 22 & 5 & 100 & \multirow{2}{*}{3,32} & \\
\hline & & Skor & 90 & 112 & 81 & 44 & 5 & 332 & & \\
\hline \multirow{2}{*}{$\begin{array}{l}\text { Pencarian } \\
\text { Informasi }\end{array}$} & & Frek & 12 & 33 & 32 & 17 & 6 & 100 & \multirow{2}{*}{3,28} & \multirow{2}{*}{ Sedang } \\
\hline & 1 & Skor & 60 & 132 & 96 & 34 & 6 & 328 & & \\
\hline \multirow{6}{*}{$\begin{array}{l}\text { Evaluasi } \\
\text { Altematif } \\
\text { Keputusan } \\
\text { Pembelian } \\
\text { Perilaku } \\
\text { Pasca } \\
\text { Pembelian }\end{array}$} & 1 & Frek & 22 & 37 & 29 & 11 & 1 & 100 & \multirow{2}{*}{3,68} & \multirow{2}{*}{ Tinggi } \\
\hline & 1 & Skor & 110 & 148 & 87 & 22 & 1 & 368 & & \\
\hline & 1 & Frek & 14 & 34 & 30 & 15 & 7 & 100 & \multirow{3}{*}{3,33} & \multirow{2}{*}{ Sedang } \\
\hline & & Skor & 70 & 136 & 90 & 30 & 7 & 333 & & \\
\hline & \multirow[b]{2}{*}{1} & Frek & 22 & 41 & 33 & . & 4 & 100 & & \multirow[b]{2}{*}{ Tinggi } \\
\hline & & Skor & 110 & 164 & 99 & - & 4 & 377 & 377 & \\
\hline \multirow{2}{*}{ Total } & & Frek & 105 & 182 & 83 & 83 & 4 & 600 & \multirow{2}{*}{3,45} & \multirow{2}{*}{ Tinggi } \\
\hline & & Skor & 525 & 808 & 546 & 166 & 4 & 2068 & & \\
\hline
\end{tabular}

Dari Tabel 4 menunjukkan bahwa variabel yang paling mendominasi pernyataan keputusan pembelian dengan skor mean 3,77 adalah variabel perilaku pasca pembelian dengan pernyataan berbelanja di indomaret memberikan saya kepuasan dan kenyamanan, pernyataan ini dapat diartikan bahwa konsumen yang telah berbelanja di Minimarket Indomaret merasa puas baik dari segi pelayanan dan kenyamanan tempat yang diberikan. Adapun pelayanan dan kenyaman yang diberikan seperti pelayanan kasir yang baik, kondisi minimarket yang bersih dan dingin dan kualitas produk yang baik.

Berdasarkan hasil uji korelasi dan koefisien determinasi diperoleh hasil sebagai berikut:

Tabel 4. Hasil Uji Koefisien korelasi dan koefisien determinasi

\begin{tabular}{|ccccc|}
\hline Model & R & R Square & $\begin{array}{c}\text { AdjustedR } \\
\text { Square }\end{array}$ & $\begin{array}{c}\text { Std. Error of the } \\
\text { Estimate }\end{array}$ \\
\hline 1 & $0,649^{2}$ & 0,421 & 0,415 & 3,826 \\
\hline
\end{tabular}

Sumber: Data Olahan SPSS 22.
Berdasarkan Tabel 5 diatas menjelaskan besarnya nilai korelasi atau hubungan $(\mathrm{R})$ adalah sebesar 0,649, dan diperoleh besar $\mathbf{R}$ square atau disebut dengan koefisien determinasi (KD) adalah sebesar 0,421 atau sama dengan $42,1 \%$ yang mengandung pengertian bahwa pengaruh variabel bebas (Iklan katalog) terhadap variabel terikat (Keputusan pembelian) adalah sebesar $42,1 \%$. Jadi dapat dikatakan bahwa 42,1\% variabel yang mempengaruhi keputusan pembelian di Minimarket Indomaret adalah iklan katalog, sedangkan $57.9 \%(100 \%$ - 42,1\%) sisanya disebabkan oleh variabel lain selain iklan katalog yang tidak dibahas dalam penelitian ini. Kemudian dilakukan uji signifikansi dan uji persamaan regresi diperoleh hasil sebagai berikut:

Table 5. Uji t Hitung Signifikansi dan persamaan regresi

\begin{tabular}{|c|c|c|c|c|c|}
\hline \multirow[t]{2}{*}{ Model } & \multicolumn{2}{|c|}{$\begin{array}{l}\text { Unstandardized } \\
\text { coefficients }\end{array}$} & $\begin{array}{l}\text { Standardized } \\
\text { coefficients }\end{array}$ & \multirow[t]{2}{*}{$t$} & \multirow[t]{2}{*}{ Sig. } \\
\hline & B & StdError & Beta & & \\
\hline 1 (Constant) IKlan & 4,375 & 1,978 & & 2,212 & 0,029 \\
\hline Katalog & 0,861 & 0,102 & 0,649 & 8,440 & 0,000 \\
\hline
\end{tabular}

Table 6. Hasil perhitungan Uji Signifikansi (t test) parsial antara variabel Iklan Katalog terhadap Keputusan Pembelian, a- $=0,05$

\begin{tabular}{|cccccc|}
\hline $\mathrm{H}$ & Variabel & $\mathbf{t}_{\text {birug }}$ & Signifikan & $\begin{array}{c}\mathbf{t}_{\text {tubl }} \\
\text { df } 98\end{array}$ & $\begin{array}{c}\boldsymbol{u}=0,05 \\
\text { (dua sisi) }\end{array}$ \\
\hline 100 & IKlan Katalog $(\mathrm{X})$ & 8,440 & 0,000 & 1,984 & 0,05 \\
\hline
\end{tabular}

Sumber: Data Olaban SPSS 22.

Konstanta sebesar 4,375 mengandung arti bahwa konsisten variabel keputusan pembelian adalah sebesar 4,375. Apabila iklan katalog meningkat sebesar satu satuan maka keputusan pembelian meningkat sebesar 0,861 . hal ini menunjukkan pengaruh yang positif dan signifikan antara Iklan katalog dan keputusan pembelian. sehingga hipotesis alternatif Ha diterima dan Ho ditolak. Sehingga dapat disimpulkan bahwa promosi melalui iklan katalog mempengaruhi keputusan pembelian di Minimarket Indomaret di Kota Bengkalis.

\section{Kesimpulan}

Berdasarkan kesimpulan diatas, maka dapat menyajikan beberapa saran sebagai referensi yakni sebagai berikut:

a) Mengingat tingginya pengaruh iklan katalog terhadap keputusan pembelian diharapkan 
Minimarket Indomaret mempertahankan serta meningkatkan kualitas dan kuantitas promosi melalui periklanan, agar dapat meningkatkan jumlah pembelian.

b) Penelitian ini dapat dikembangkan lagi dengan memperluas lingkup responden dan menambah variabel lain selain iklan katalog. Peneliti selanjutnya juga dapat menggunakan metode lain dalam melakukan penelitian, misalnya melalui wawancara yang mendalam kepada responden. Sehingga informasi yang diperoleh dapat lebih bervariasi daripada kuesioner yang jawabannya telah tersedia.

\section{Daftar Pustaka}

Binalay, Mandey dan Mintardjo (2016) "Pengaruh Sikap, Norma Subjektif Dan Motivasi Terhadap Minat Beli Secara Online Pada Mahasiswa Fakultas Ekonomi Dan Bisnis di Manado", Jurnal EMBA, 4(1), 395-406.

Darmawan dan Suharyono (2019) "Tingkat Kepuasan Konsumen Dalam Menggunakan Smartphone Merek Xiaomi Pada Mahasiswa Politeknik Negeri Bengkalis", Jurnal Inovasi Bisnis, 7(2), 131-137.

Hermawan (2015) “Analisis Pengaruh Bauran Pemasaran Terhadap Keputusan, Kepuasan Dan Loyalitas Konsumen Dalam Pembelian Roti Ceria Di Jember", Jurnal Manajemen Dan Bisnis Indonesia, 1(2), 143-161.

Heryanto (2015) “Analisis Pengaruh Produk, Harga, Distribusi, Dan Promosi Terhadap Keputusan Pembelian Serta Implikasinya Pada Kepuasan Pelanggan", Jurnal Ekonomi, Bisnis \& Entrepreneurship, 9(2), 80-101.

Hanum dan Hidayat (2017) "Faktor-Faktor Yang Mempengaruhi Perilaku Konsumen Dalam Keputusan Pembelian Sepatu Merek Nike Di Kota Medan", Jurnal Bisnis Administrasi, 6(1), 37-43.
Kuspriyono (2018) "Pengaruh Iklan Terhadap Keputusan Pembelian Apartemen Meikarta", Cakrawala, 18(1), 59-66.

Moloku, Tampi dan Walangitan (2019) "Pengaruh Iklan Terhadap Keputusan Pembelian Produk Smartphone Oppo Di IT Center Manado", Jurnal Administrasi Bisnis, 8(2), 98-106.

Ng'etich dan Auka (2019) "Influence of Advertising on Consumer Purchase Decision Of Sport Betting: A Case Study Of Students In Nakuru Town University Campuses, Kenya", International Journal of Business Management \& Finance, 3(2), 236-257.

Sugiyono. (2016) "Metode Penelitian Administrasi dilengkapi dengan Metode R\&D”, Alfabeta, Bandung.

Sugiyono. (2016) Metodologi Penelitian Kuantitatif, Kualitatif Dan R\&D. Alfabeta, Bandung.

Santosa dan Fatma (2019) "Pengaruh Iklan Terhadap Keputusan Pembelian Merchandise C-corner Di PT. Kereta Commuter Indonesia Jakarta", Jurnal Bisnis dan Pemasaran, 9(2), 88-98.

Sidabalok dan Andriyani (2020) "Pengaruh Iklan Katalog Terhadap Keputusan Pembelian Di Indomaret Sindangsari Tanjung Bintang", GEMA, 12(1), 75-83.

Tumulo (2017) "Pengaruh Iklan Dan Positioning Merek Terhadap Keputusan Pembelian Konsumen Minuman Coca Cola Pada Indomaret Mmtc Jl. Williem Iskandar Medan", JURNAL PLANS, 12(1), 76-87. 